http://journal.nafo.int

J. Northw. All. Fish. Sci., Vol. 6: 107-116

\title{
Validation and Application of an Ageing Technique for Short-finned Squid (Illex illecebrosus)
}

\author{
E. G. Dawe \\ Fisheries Research Branch, Department of Fisheries and Oceans \\ Northwest Atlantic Fisheries Centre, P. O. Box 5667 \\ St. John's, Newfoundland, Canada AIC $5 \times 1$ \\ R. K. O'Dor \\ Department of Biology, Dalhousie University \\ Halifax, Nova Scotia, Canada B3H $3 J 1$ \\ P. H. Odense \\ Atlantic Research Laboratory, National Research Council of Canada \\ Halifax, Nova Scotia, Canada B3H $3 Z 1$ \\ G. V. Hurley \\ Hurley Fisheries Consulting, P. O. Box 3049, East Postal Station \\ Dartmouth, Nova Scotia, Canada B2W 4Y2
}

\begin{abstract}
A technique has been developed which simplifies the ageing of short-finned squid (/Ilex illecebrosus) through microstructural examination of the statoliths. The spatial pattern of growth increments was studied with the use of light and scanning electron microscopy. Daily growth increments in statoliths were validated by employing chemical "time" markers (strontium and tetracycline) and laboratory-reared animals of known age. Increment formation continued through periods of food deprivation and minimal temperature fluctuations.
\end{abstract}

\section{Introduction}

Attempts to validate the ageing of short-finned squid (IIlex illecebrosus) have involved comparing the difference in statolith increment counts and the number of days that have elapsed between the capture dates of samples of squid which were thought to belong to the same cohort (Hurley and Beck, 1979; Lipinski, 1980; Radtke, 1983; Morris and Aldrich, 1985). Interpretation of statolith increment counts is complicated by variation in the technical procedures used to prepare and examine the statoliths, possible irregularities in increment formation due to physiological stress, or the presence of mixed age-groups within a single year-class (Dawe, 1981).

Hurley and Beck (1979) and Dawe (1981) recognized the possibility of factors such as photoperiod and feeding rate being involved in statolith increment formation. They suggested a more direct approach such as the use of material of known age and chemical labelling, which are used commonly in fish age validation (Brothers et al., 1976; Campana and Neilson, 1982 ), as a basis for age validation in squid.

Specific objectives of this study of age validation in squid were: (a) to simplify the preparation of squid statoliths for ageing and to test the accuracy of age validation; (b) to employ strontium (Hurley et al., 1985) and tetracycline as temporal markers to validate daily growth increments under controlled conditions and feeding regimes; (c) to determine the age when increment formation begins by examining the statoliths of laboratory-reared larvae of known age; (d) to evaluate the importance of feeding regime to the rate of increment formation; and (e) to compare daily increment counts in squid from inshore and offshore areas in an attempt to determine the age composition of samples from the different areas.

\section{Materials and Methods}

\section{Marking experiments}

Squid with mantle lengths from 21.5 to $28.0 \mathrm{~cm}$ were obtained from a trap-net in St. Margaret's Bay, near Halifax, Nova Scotia, during October-November of 1982 and 1983. They were transported to Dalhousie University, Halifax, and placed in a seawater tank at the Aquatron Laboratory, which was described by O'Doret al. (1977). The squid were maintained in the tank under controlled photoperiod ( $16 \mathrm{hr}$ light and $8 \mathrm{hr}$ darkness) in 1982 and under natural photoperiod (10 hr light and $14 \mathrm{hr}$ darkness) in 1983. Water temperature was maintained between $12^{\circ}$ and $15^{\circ} \mathrm{C}$ and salinity between 30.8 and 32.1 during the experiments. 
TABLE 1. Experimental observations on statoliths of captive 1. illecebrosus that were marked with strontium and tetracycline $\mathrm{HCl}$. (Squid were held under constant photoperiod (day $16 \mathrm{hr}$, night $8 \mathrm{hr}$ ) and fed daily in 1982, and under natural photoperiod without feeding in 1983.)

\begin{tabular}{|c|c|c|c|c|c|c|c|}
\hline $\begin{array}{l}\text { Mantle } \\
\text { length } \\
(\mathrm{cm})\end{array}$ & Sex & $\begin{array}{l}\text { Marking } \\
\text { method }\end{array}$ & $\begin{array}{c}\text { Date } \\
\text { marked }\end{array}$ & $\begin{array}{l}\text { Date } \\
\text { died }\end{array}$ & $\begin{array}{c}\text { Elapsed } \\
\text { time } \\
\text { (days) }\end{array}$ & $\begin{array}{c}\text { Number } \\
\text { of } \\
\text { increments }\end{array}$ & $\begin{array}{l}\text { Increment } \\
\text { mean width } \\
(\mu \mathrm{m})\end{array}$ \\
\hline 21.5 & $M$ & Tetracycline & 19 Nov 82 & 23 Nov & 4 & 4 & 2.5 \\
\hline \multirow[t]{2}{*}{22.0} & $M$ & Strontium & 13 Nov 82 & 27 Nov & 14 & 11 & 2.8 \\
\hline & & Tetracycline & 19 Nov 82 & 27 Nov & 8 & 8 & 3.1 \\
\hline \multirow[t]{3}{*}{24.0} & $\mathrm{~F}$ & Strontium & 13 Nov 82 & $04 \mathrm{Dec}$ & 21 & 20 & 1.7 \\
\hline & & Strontium & 15 Nov 82 & 04 Dec & 19 & 18 & 1.7 \\
\hline & & Tetracycline & 19 Nov 82 & $04 \mathrm{Dec}$ & 15 & 13 & 1.4 \\
\hline 24.0 & $F$ & Tetracycline & 19 Nov 82 & $08 \mathrm{Dec}$ & 19 & 16 & 2.6 \\
\hline \multirow[t]{2}{*}{24.8} & $\mathrm{~F}$ & Tetracycline & 19 Nov 82 & 13 Dec & 24 & 24 & 2.1 \\
\hline & & Strontium & 01 Dec 82 & $13 \mathrm{Dec}$ & 13 & 13 & 2.0 \\
\hline 26.0 & $\mathrm{~F}$ & Tetracycline & 17 Nov 83 & $20 \mathrm{Nov}$ & 3 & 3 & 3.6 \\
\hline 26.5 & $\mathrm{~F}$ & Strontium & 17 Nov 82 & $04 \mathrm{Dec}$ & 17 & 17 & 2.2 \\
\hline 28.0 & $F$ & Tetracyciline & 21 Nov 83 & 27 Nov & 6 & 6 & 1.8 \\
\hline
\end{tabular}

Squid to be marked with strontium were fed one or two whole, cooked shrimp which had been soaked for $24 \mathrm{hr}$ in a solution of $1.2 \mathrm{~g}$ of strontium chloride per $\mathrm{ml}$ of distilled water. In 1982, squid to be marked with tetracycline were fed shrimp which were stuffed with $75 \mathrm{mg}$ of oxytetracycline $\mathrm{HCl}$, whereas, in 1983, they were forced-fed a solution of $0.5 \mathrm{ml}$ of oxytetracycline in $1.5 \mathrm{ml}$ of seawater. Identification of individuals was possible through recognition of specific skin abrasion patterns that were peculiar to each animal. In 1982, the squid after marking were fed liberally once daily (morning) with untreated shrimp. In 1983, the squid were not fed after marking with a view to determining if growth increments were formed during a period of starvation. In both years, the marked squid were maintained until they died naturally, the duration between time of marking and death ranging from 3 to 24 days (Table 1). After death, the mantle length and sex of each specimen were recorded, and the statoliths were extracted and prepared for microscopic examination.

\section{Known-age specimen}

One of the squid in the Aquatron pool produced an egg mass on 7 November 1983. The eggs were maintained at $25^{\circ} \mathrm{C}$ and hatching occurred 6 days later. All of the larvae had died by 16 November, probably due to lack of food (O'Dor, 1983). One of the oldest larvae (3 days after hatching) was preserved immediately after death in $75 \%$ ethanol. It was processed for histological examination by immersion in a succession of ethanol rinses of increasing concentration from 80 to $100 \%$, cleared in xylene, and embedded in paraffin wax. Microtome sections (6 $\mu \mathrm{m}$ thick) were prepared and stained with Mallory's Triple Stain (Pantin, 1960).

\section{Inshore and offshore samples}

Four samples of squid were collected from the inshore jigger fishery at Holyrood, Conception Bay,
Newfoundland, during 23 July-31 August 1982. Two samples were collected from offshore otter trawl catches on the Scotian Shelf in June and August 1982 and four offshore samples were obtained in June, August, September and November 1983. Where possible, statoliths were extracted from 10 squid of each sex from the modal length $(1-\mathrm{cm})$ group and two specimens from each of the remaining $1-\mathrm{cm}$ length groups of each sample (Fig. 1). Only the left statolith from each squid was utilized because the increment counts in the left and right statoliths do not differ significantly (Lipinski, 1980). By selecting squid with mantle lengths which corresponded to the precise mode (within $1 \mathrm{~cm}$ ) of the length frequency of the sample (compared to random sampling or modal approximation in earlier studies), it was thought that a single cohort of squid could be studied more effectively as it progressed through the season.

\section{Statolith preparation}

A transverse cut through the statocyst exposed the paired statoliths in their maculae. After removal, the statoliths were immersed in distilled water for approximately $24 \mathrm{hr}$ before mounting and viewing under a microscope. Other premounting treatments (e.g. immersion in trypsin-papain for $0.25-24 \mathrm{hr}$ at $35^{\circ} \mathrm{C}$, adsolute alcohol, and glycerin) were equally effective in preventing the thin outer membrane from becoming dry, which rendered it opaque to transmitted light. Prolonged exposure to sodium hypochlorite, which has been used successfully to "chemically" extract statoliths from the skull (Hurley and Beck, 1979), had a bleaching effect and made the statoliths unreadable. Several mounting media, namely Permount, Protexx, Cover Bond, EPON, Eukitt, and Canada Balsam, were found to be suitable for viewing growth increments. However, Protexx was used during this study because it resisted cracking and chipping during grinding (unlike Permount and Cover Bond), it hardened quite 
A

Newfoundland 1982

(Inshore)

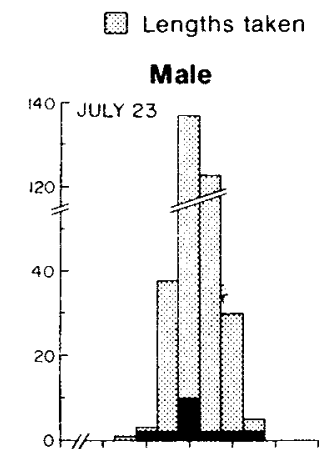

Statoliths extracted
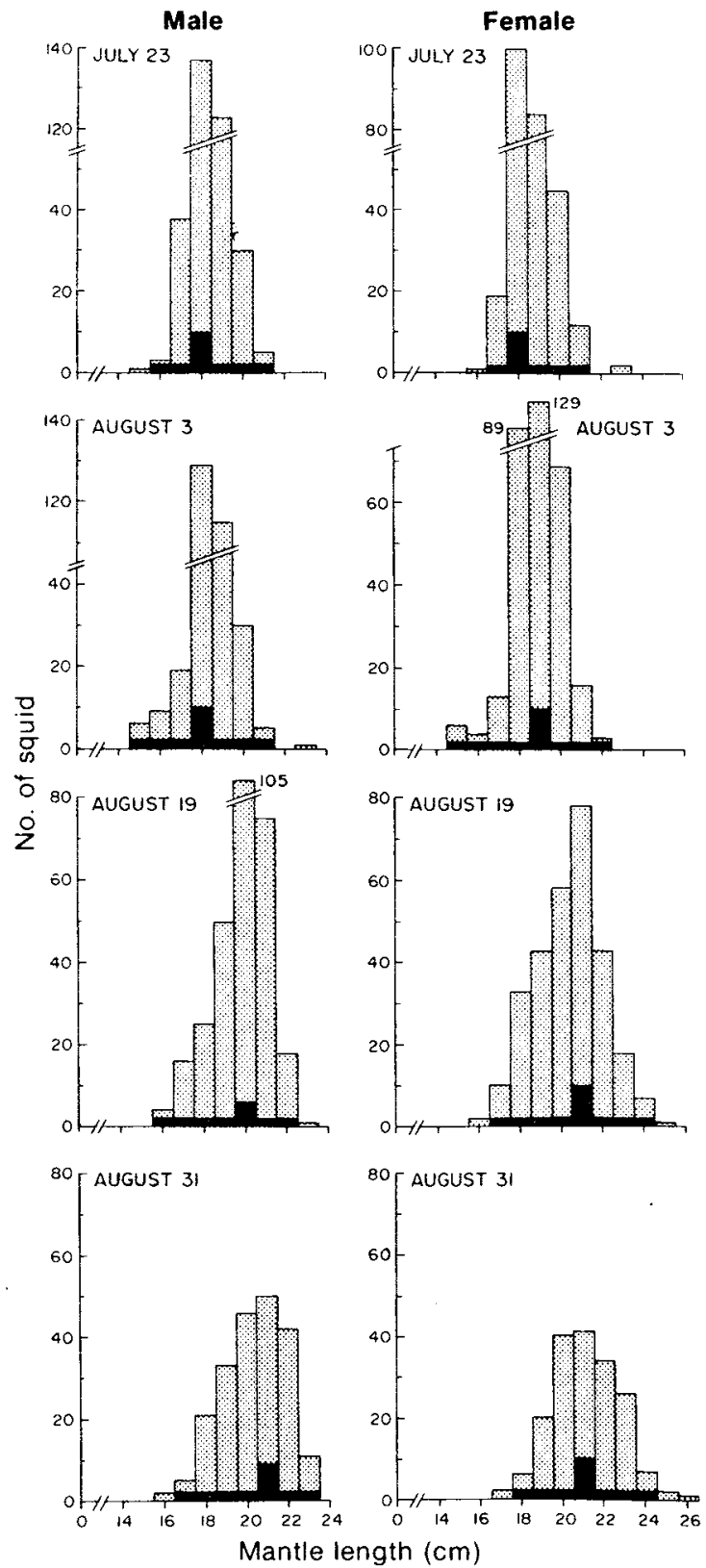

B

Nova Scotia 1982

(Offshore)

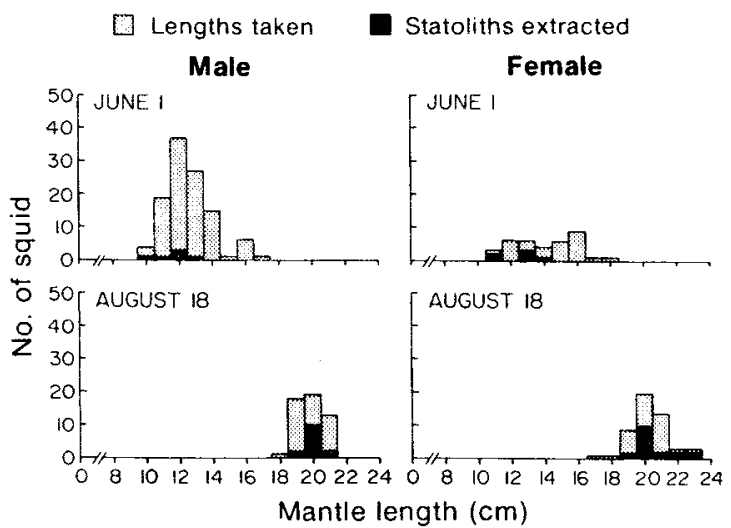

C

Nova Scotia 1983

(Offshore)
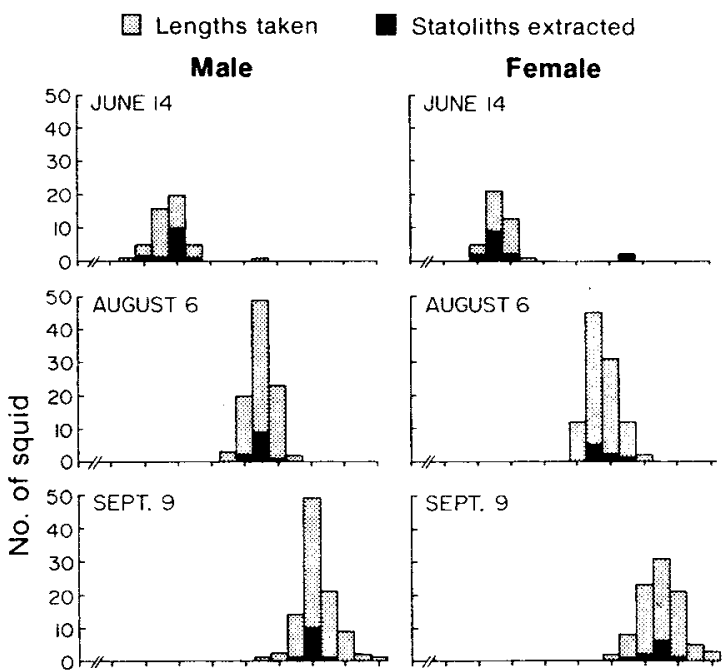

SEPT. 9
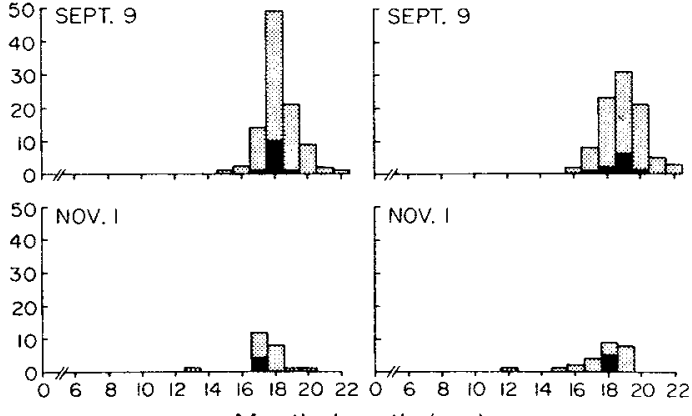

Mantle length $(\mathrm{cm})$

Fig. 1. Length distributions of $/$. illecebrosus by sex and those from which statoliths were extracted in samples from (A) inshore Newfoundland waters in 1982, and from (B and C) offshore Scotian Shelf waters in 1982 and 1983.

quickly in $24 \mathrm{hr}$ (unlike Canada Baisam), it did not require formula preparation or thermal setting (unlike EPON), and it was locally available (unlike Eukitt).

In preliminary trials, the total number of growth increments in about $5 \%$ of the statoliths could be counted without grinding, by viewing mounted specimens with the anterior concave side of the statolith facing upwards. However, in most mounts of whole statoliths, complete counting was not possible because some of the increments were obscured by occulting crystals and fragments of the outer membrane (Fig. 2A). The occulting crystals were located on the anterior surface of the statolith about 40-70 increments from the core and interferred with increment counts in all except the statoliths from very small juvenile squid (Fig. 2B).

To investigate the microstructure of the occulting crystals and statolith membrane, a scanning electron 

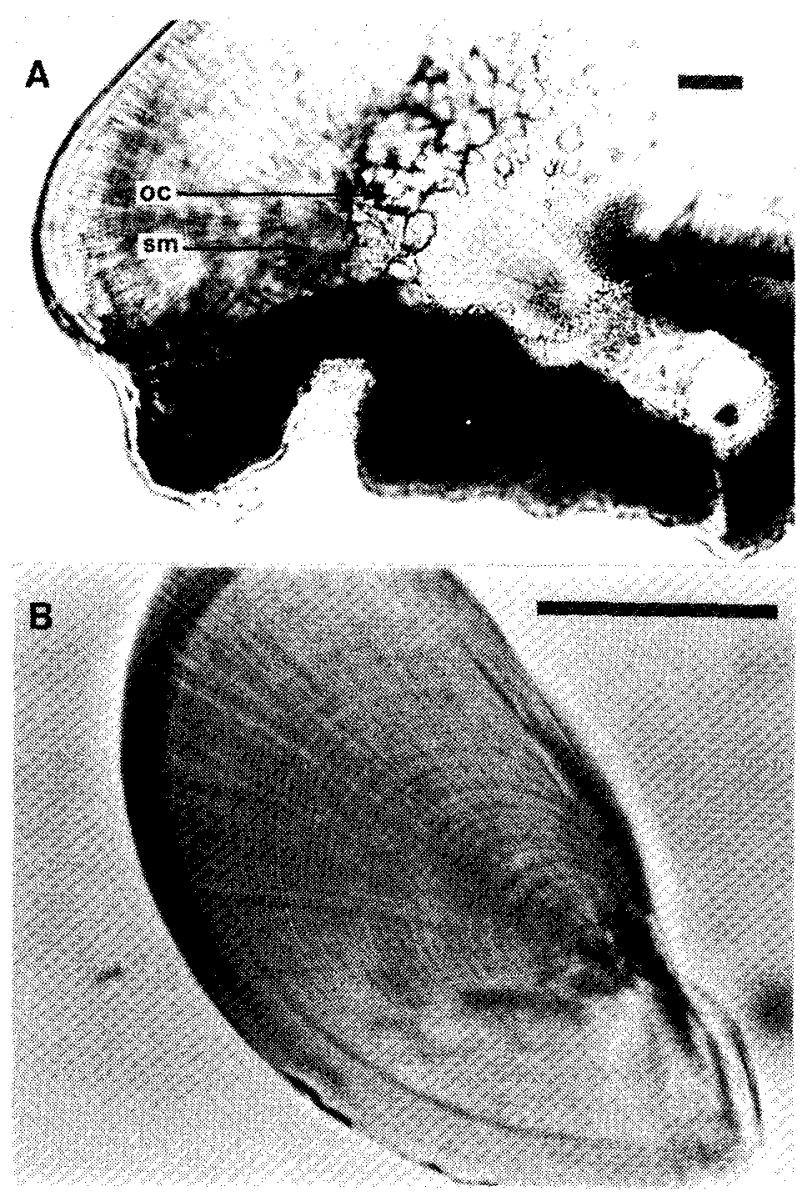

Fig. 2. Light micrographs of anterior, concave view of I. illecebrosus statoliths from (A) $12 \mathrm{~cm}$ squid showing occulting crystals $(\mathrm{OC})$ and fragments of statolith membrane $(\mathrm{sm})$ which obscure some increments (bar $=62.9 \mu \mathrm{m}$ ); and (B) $1.1 \mathrm{~cm}$ squid before formation of occulting crystals ( $\mathrm{bar}=100 \mu \mathrm{m}$ ).

microscope (Bausch and Lomb Nanolab 2000) was employed. In preparation, the statolith was fixed immediately after extraction in glutaraldehyde buffered with seawater, followed by dehydration in a series of increasing concentrations (50-100\%) of ethanol and critical-point drying. It was then glued to an aluminum stub with Epoxy and coated with gold. Microscopic examination revealed that the membrane had peeled off the main portion of the statolith in patches (Fig. 3A), exposing the tips of the underlying calcium carbonate crystals which met the surface at right angles. The occulting crystals appeared as prominent clumps which were partially covered by the irregularlyarranged crystals of the wing (Fig. 3B). The latter crystals made the wing appear dark in a light micrograph (Fig. 2A) because they prevented the transmission of light.

Morris and Aldrich (1985) pointed out that, when the concave side of the statolith faced upward, grinding through the occulting crystals often obliterated the increments below. Another approach, which facititates
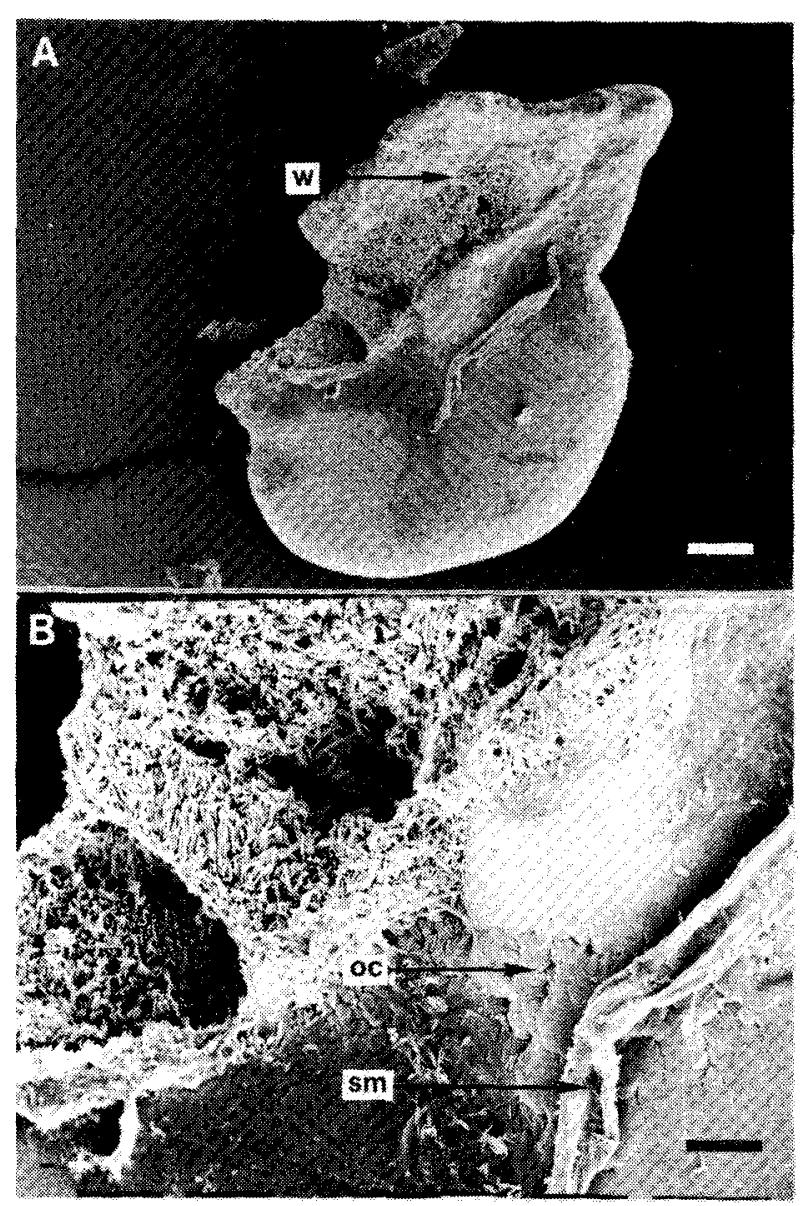

Fig. 3. Scanning electron microscope micrographs of the statolith from a 22-cm 1. illecebrosus: (A) anterior right side view showing wing $(w)$ and outer membrane which has peeled off in patches (bar $=152 \mu \mathrm{m}$ ); (B) view of wing area showing random arrangement of occulting crystals (OC) and patches of outer membrane (sm) (bar $=32 \mu \mathrm{m})$.

the viewing of all increments, including those in the region of the occulting crystals, is described here. The statolith was glued to the glass slide so that the posterior convex side of the statolith faced upward. Grinding was necessary to facilitate the counting of all increments, because only a few of the outer increments could be seen in the whole mount. Grinding proceeded by using a succession of increasingly-finer grit carborundum paper down to $3 / 0$ polishing paper until the first clear increment outside the core (Fig. 4A) and those lying above the occulting crystals (Fig. 4B) were clearly visible by focusing down through the statolith. The process was expedited by grinding several statoliths on a single slide at the same time. With this procedure, up to six statoliths of similar size were successfully prepared for age determination. A thin film of water over the ground surface helped to improve the resolution of the increments by filling the small cracks and acting as a liquid "coverslip". For the marked statoliths, grinding continued until the increments distal to the marker were exposed along the maximum radius. 

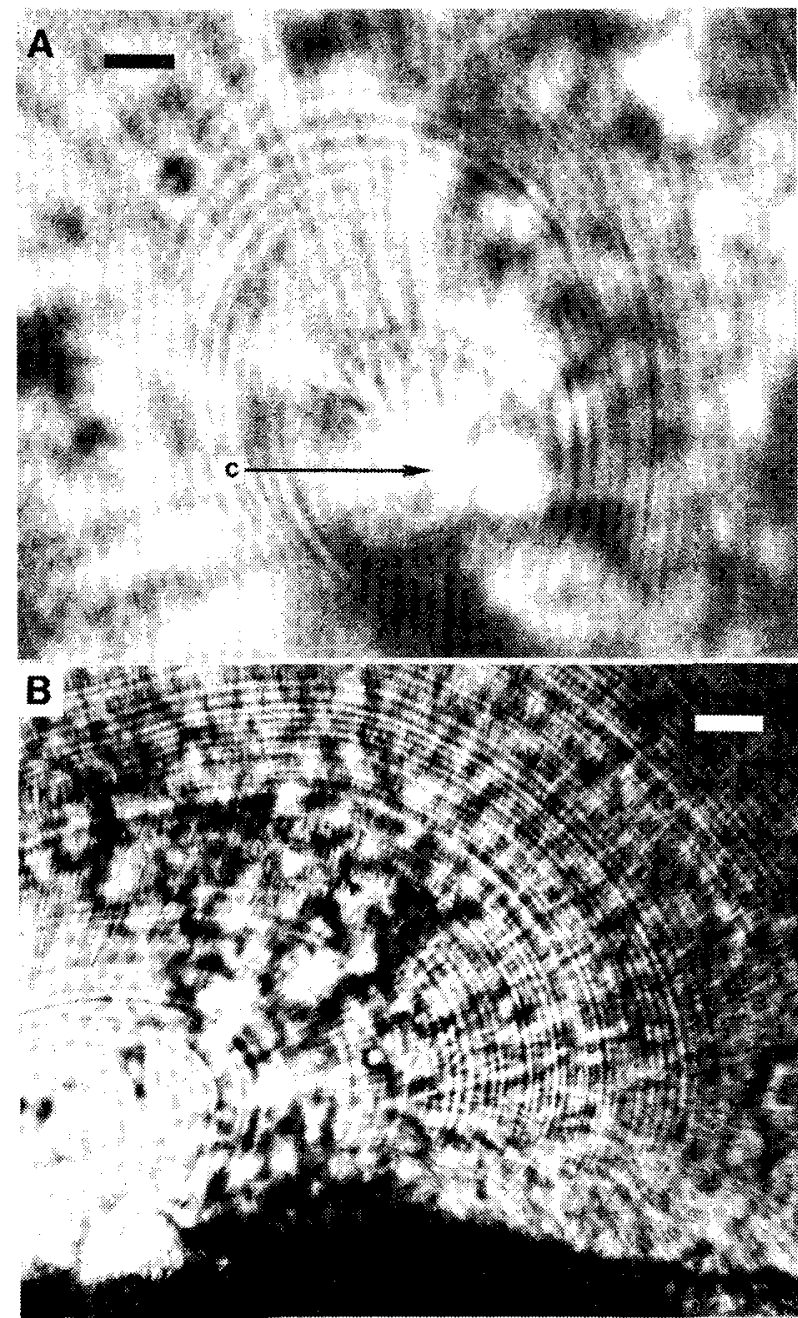

Fig. 4. Light micrographs of I. illecebrosus statoliths which were ground on the posterior convex side, showing $(\mathbf{A})$ increments around the core (c) but none within the core (bar $=9.2 \mu \mathrm{m})$, and $(8)$ increments lying above the occulting crystals (bar= $28 \mu \mathrm{m})$.

The growth increments, which were defined as "bipartite" structures composed of one opitcally transparent and one less transparent layer" (Brothers et al., 1983), were best viewed with the microscope properly adjusted to ensure Kohler illumination and containing a condenser diaphragm which was almost completely closed. A single polarizing filter, which could be rotated for maximum clarity in the direction of interest, and a green filter also helped.

Optical sectioning (i.e. focusing to the plane of clarity) (Fig. 2B, 4B) indicated that all increments were not visible on the same plane. As further proof of this, the statolith was ground down to the core region so that the increments would be exposed by acid etching under the scanning electron microscope. This involved polishing the ground surface with $1 \mu \mathrm{m}$ diamond paste, immersing the statolith in $1 \% \mathrm{HC} 1$ for $90-200 \mathrm{sec}$, rins-

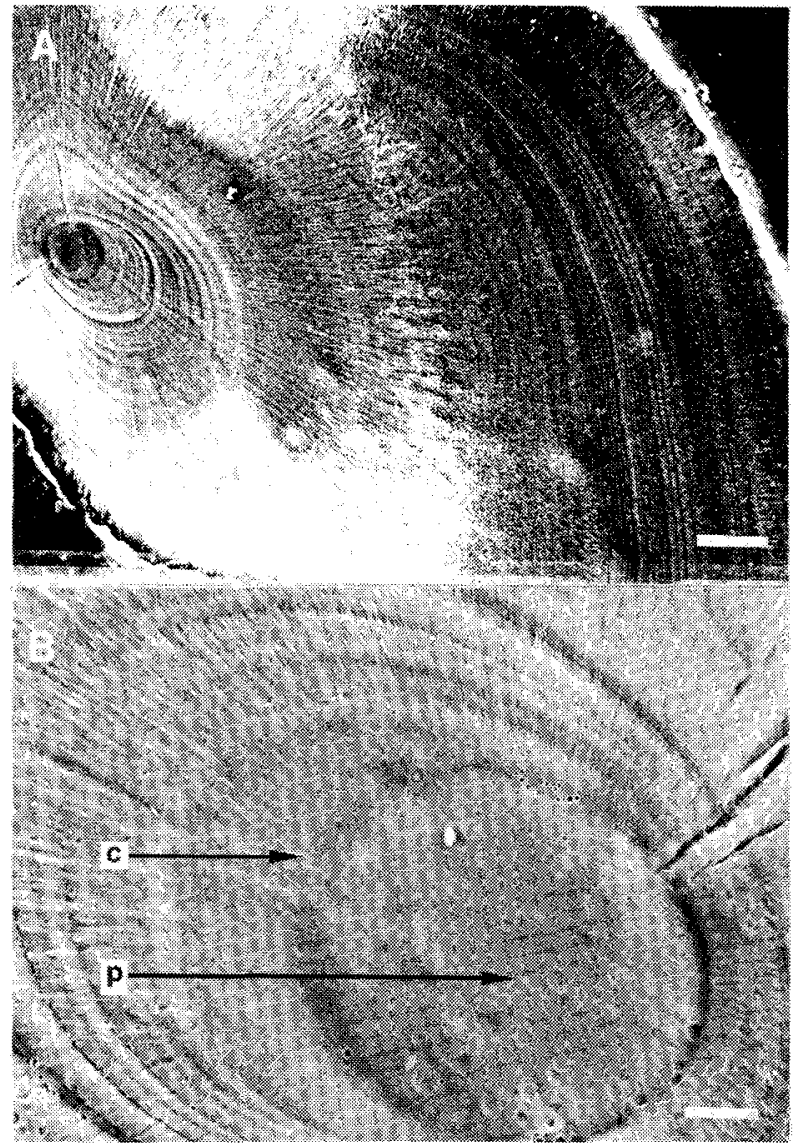

Fig. 5. Scanning electron microscope micrograph of acid-etched increments on the ground surface of a statolith from a $19-\mathrm{cm}$ 1. illecebrosus: (A) view of the plane through the core region (bar $=34.4 \mu \mathrm{m})$, and $(\mathbf{B})$ increments in the immediate vicinity of the core (c) and primordium (p) (bar $=4.7 \mu \mathrm{m}$ ).

ing and coating it with gold. Increments were not visible in several areas (Fig. 5A). The core and the primordium (terminology according to Brothers et al., 1983) (Fig. 5B) were difficult to locate, indicating that they were relatively thin. Examination of a statolith which had been fractured along its posterodorsal axis (i.e. perpendicular to the normal grinding plane) (Fig. 6) revealed that the calcium carbonate crystals radiate out in different directions from the small core region to meet the surface of the statolith at right angles. Presumably, only crystals that are oriented in the same direction as the ground surface reveal increments when etched, as in Fig. 5A and 5B.

\section{Counting procedure}

Statoliths were viewed under a bright field with a Zeiss Phot 1 microscope that was equipped with a 35-mm camera and a drawing arm, the latter being used to map the increments. Normally, the increments could also be seen clearly in light micrographs (Fig. 4, 7A). In cases where certain increments were out of focus on the micrograph and therefore difficult to 

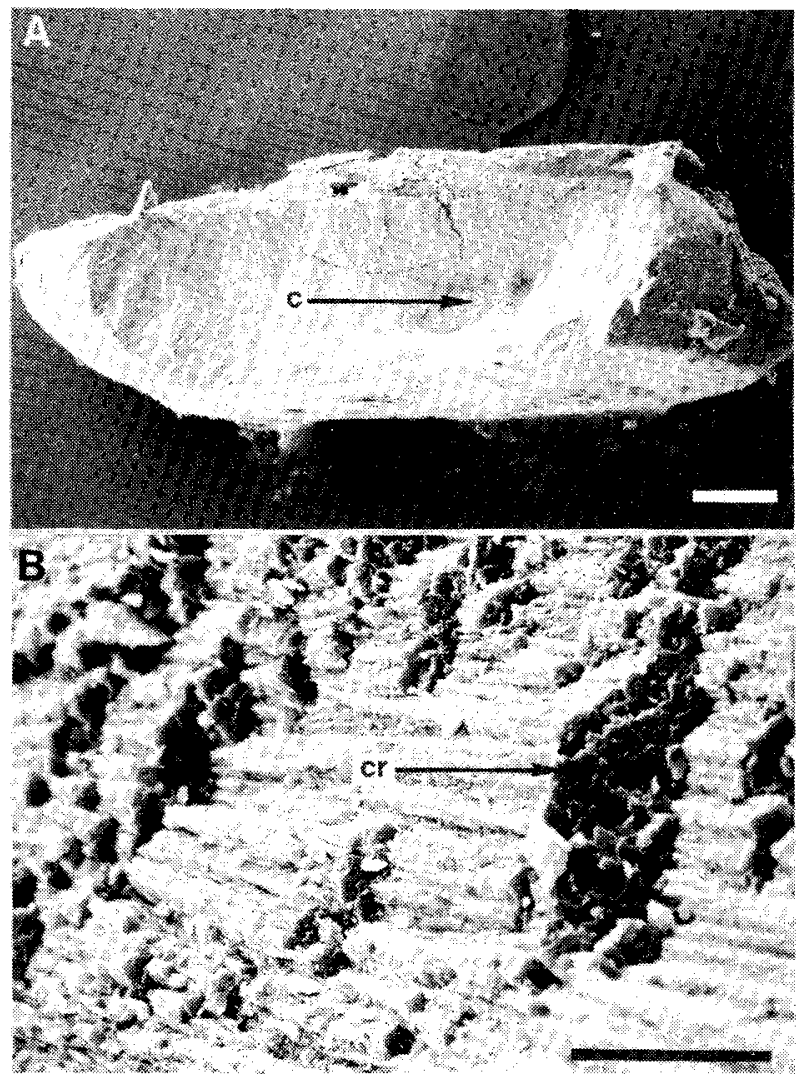

Fig. 6. Scanning electron microscope micrographs of an I. illecebrosus statolith fractured along its posterodorsal axis, showing (A) calcium carbonate crystals which radiate from the core region (c) (bar =: $100 \mu \mathrm{m}$ ); and (B) further detail ofcrystals including sheared surfaces at the ends of the crystalites (cr) $($ bar $=10 \mu \mathrm{m})$

interpret, the definitions of these were resolved by comparing maps that were made by two individuals with the drawing arm. The maximum number of visible increments was recorded by counting along the full radius (see diagram by Morris and Aldrich, 1985). Any variation in density that could possibly be considered an increment was counted. Counts which differed by no more than one increment were considered to be in agreement. The specific identity of each statolith was unknown before the increments were defined. Individual increment widths were measured on a light micrograph with the aid of a graphics tablet and an Apple llE microcomputer.

The method of detection (i.e. use of a line profile superimposed on a back-scattered electron image) and the counting procedure for statoliths that were marked with strontium were outlined by Hurley et al. (1985). Tetracycline fluorescence by incident illumination was detected with the use of a No. 2 exciter filter $(350 \mathrm{~nm})$ and a No. 50 barrier filter $(500 \mathrm{~nm})$. Age validation counts were made by projecting the ultraviolet image (Fig. 7B) on its respective light micrograph (Fig. 7A) and counting the number of increments
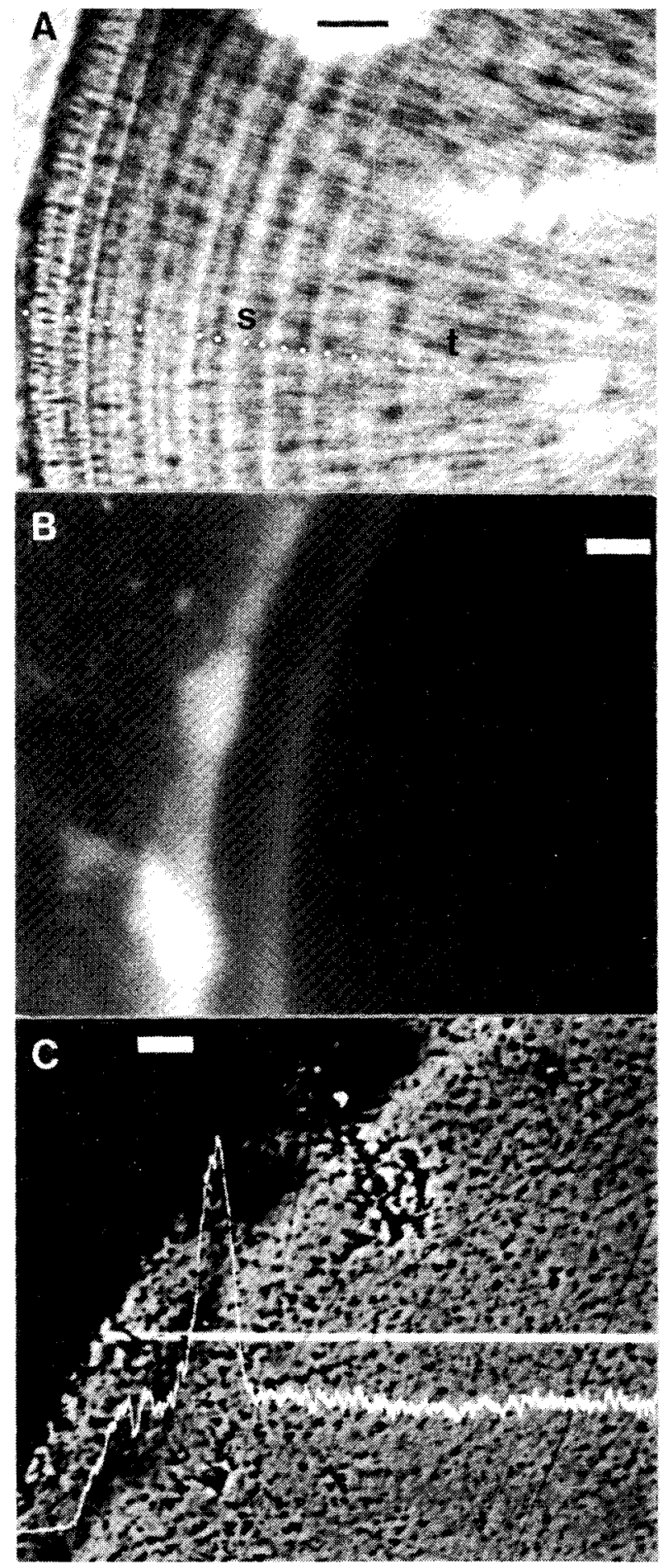

Fig. 7. Micrographs of a ground I. illecebrosus statolith marked with tetracycline on 19 November and with strontium on 1 December 1982 (Table 1): (A) bright film illumination showing daily increments and positions of the strontium (s) and tetracycline (t) labels (bar $=10 \mu \mathrm{m}$ ); (B) ultraviolet light showing tetracycline fluorescence as a bright band (bar $=27.7 \mu \mathrm{m}$ ); and (C) scanning electron microscope micrograph showing strontium $x$-ray line profile superimposed on back-scattered electron image of the strontium band (bar $=10 \mu \mathrm{m}$ ) (from Hurley et al., 1985) 
from the proximal edge of the fluorescent band to the outer edge of the statolith. The sections in Fig. 7 were from a statolith which had been marked successively with tetracycline and strontium.

\section{Results and Discusssion}

\section{Known-age larva}

The statolith of the 3-day-old specimen (from hatching) is shown attached to the wall of the statocyst (Fig. 8). Its maximum diameter $(27.4 \mu \mathrm{m})$ corresponds to the size of the statolith primordium $(27.7 \mu \mathrm{m})$ from an adult specimen (Fig. 5B). The first growth increment was not visible at this stage. Thus, this observation does not support the conclusion of Radtke (1983) that increment deposition begins at the time of hatching or the presumption of Morris and Aldrich (1985) that approximately 40 increments are laid down prior to hatching.

\section{Marked statoliths}

The statoliths of eight squid were successfully labelled with chemical markers (Table 1). Overall, there was very good agreement between the number of growth increments formed after labelling and the elapsed time in days. Where deviations occurred, the increment count was lower than the number of elapsed days, the maximum deviation being 3 days. This may have been due to missing very faint increments or to errors in locating the precise places on the statolith surface to start and end the counting. In this regard, Hurley et al. 1985 discussed the relative merits of strontium and tetracycline. The results from both techniques are presented here to emphasize their consistency. Mean widths of increments distal to the markers were in the range of 1.4-3.6 $\mu \mathrm{m}$ (Table 1) which approximated the widths of the outer increments $(2.0-2.6 \mu \mathrm{m})$ in specimens that were collected from Placentina Bay, Newfoundland, during October 1981 (Morris and Aldrich, 1985).

Daily growth increments were formed in the absence of feeding (1983 specimens in Table 1). The water temperature in the tank did not fluctuate greatly or regularly on a daily basis, and the squid could not make vertical diurnal migrations. Therefore, increments deposition in the statoliths of these squid may have been internally regulated, as has been suggested in the case of fish otoliths (Taubert and Coble, 1977; Campana and Neilson, 1985).

\section{Increment counts in inshore and offshore samples}

Length-frequency and modal-progression analyses were used as the basis for comparing growth increments and the elapsed time between samples from inshore Newfoundland waters in 1982 and from offshore areas of the Scotian Shelf in 1982 and 1983 (Fig. 9). The results are similar to those that were

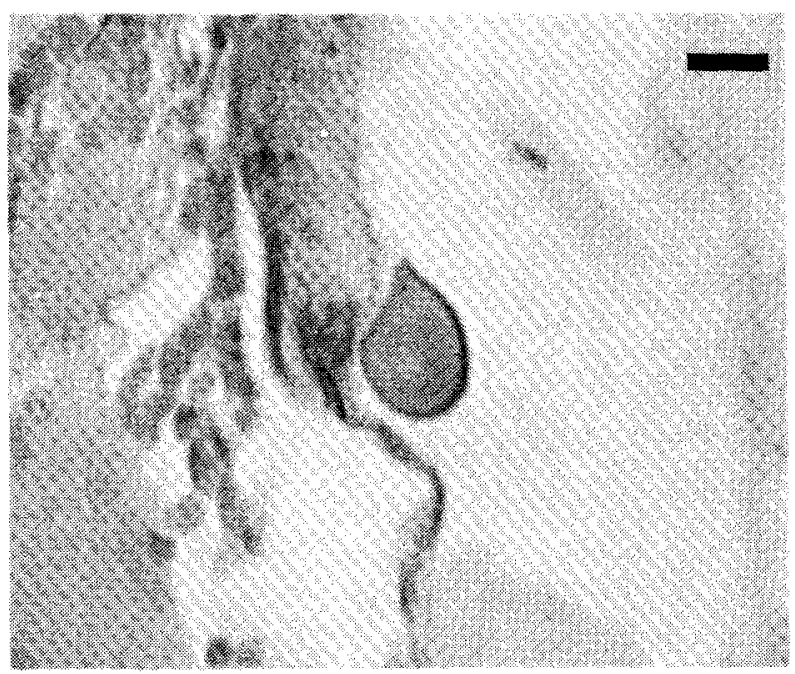

Fig. 8. Light micrograph of a $6-\mu \mathrm{m}$ histological section of a statolith attached to the statocyst wall in a 3-day-old (after hatching) laboratory-reared 1 . illecebrosus larva (bar $=13.7 \mu \mathrm{m}$ ).

reported by Hurley and Beck (1979) and by Morris and Aldrich (1985) for inshore Newfoundland samples in 1978 and 1981 respectively, and by Lipinski (1981) for samples from the Scotian Shelf in 1977. The methods of selecting samples of statoliths, i.e. by random sampling (Lipinski, 1981; Morris and Aldrich, 1985), from a range of modal lengths (Hurley and Beck, 1979), or from the precise modal lengths (this study) appear to be equally valid.

If samples from a particular location at successive times throughout the fishing season are from the same cohort of squid and if the "one increment per day" hypothesis is valid, the range increment counts for modal groups (or at least the total range) should intersect the solid line which represents the expected number of increments (Fig. 9). The data from inshore Newfoundland waters essentially meet this criterion, and projection back to age "zero" by increment count for this population indicates that they were spawned in the preceding January-February, which is consistent with the results from winter-spring surveys for larvae and juveniles (e.g. Dawe and Beck, 1985; Hatanaka et al., 1985). The data sets from the Scotian Shelf do not meet this criterion and projection back to age "zero" indicates that these squid were derived from spawning over a more protracted period. There are three plausible explanations for the deviations of increment counts from the lines in Fig. 9: (a) the true age was underestiamted because some of the outer increments in "older" squid were missed during counting; (b) increment formation in the wild occurs at less than the daily rate observed in the laboratory; and (c) the population contains mixed age-groups, or older individuals emigrate from the fishing grounds late in the year.

There are three reasons why it is unlikely that significant numbers of increments were missed during 


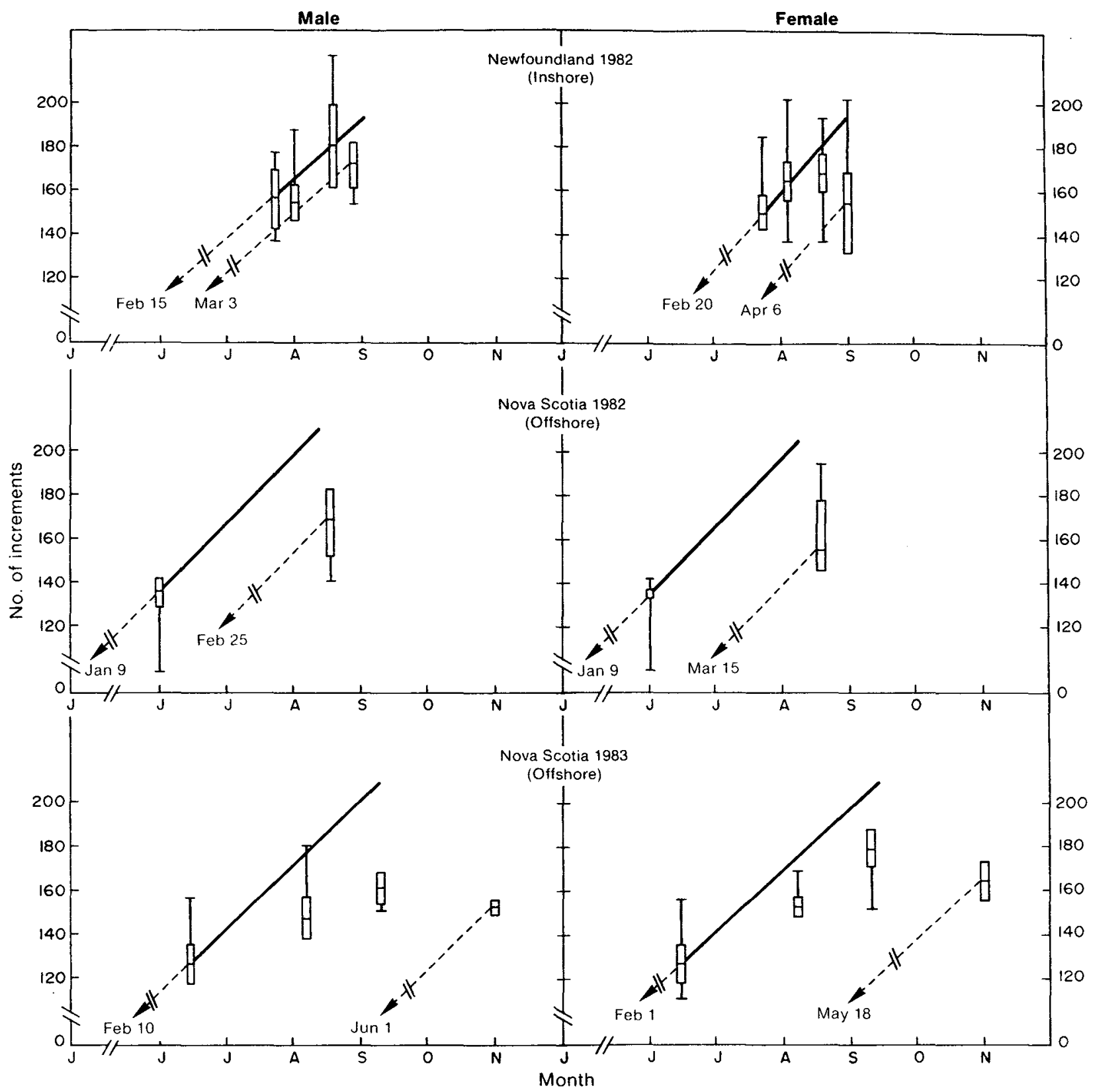

Fig. 9. Mean and range of growth increment counts in statoliths from modal size-groups of $I$. illecebrosus sampled at inshore and offshore locations in 1982 and 1983. (Oblique solid line represents the expected number of daily increments; oblique dashed line indicates the back-calculated date of formation of the first increment; vertical bar indicates range of counts for modal length group; and vertical line indicates the range for all squid.)

counting: (a) the deviations from the expected values are in some cases extremely large, especially in the case of the November 1983 sample from the Scotian Shelf where more than 100 growth increments would have been overlooked; (b) the visibility of increments in statoliths from "wild" animals is generally far superior to those from laboratory-reared specimens (our personal observations); and (c) the narrow, regular spacing of the outer increments in statoliths of older squid (Fig. 10; Morris and Aldrich, 1985) would make this zone of increments readily noticeable.
Squid that were maintained in the laboratory deposited daily growth increments in the absence of tidal or feeding cycles, daily temperature fluctuations or the opportunity to undergo extensive vertical migrations. Under natural conditions, cues to daily increment deposition would be expected to be stronger. Therefore, it is unlikely that the discrepancy between increment counts and number of days between sample collections is attributable to the formation of fewer than daily increments. The deviations are more likely due to the emigration of older individuals from the 


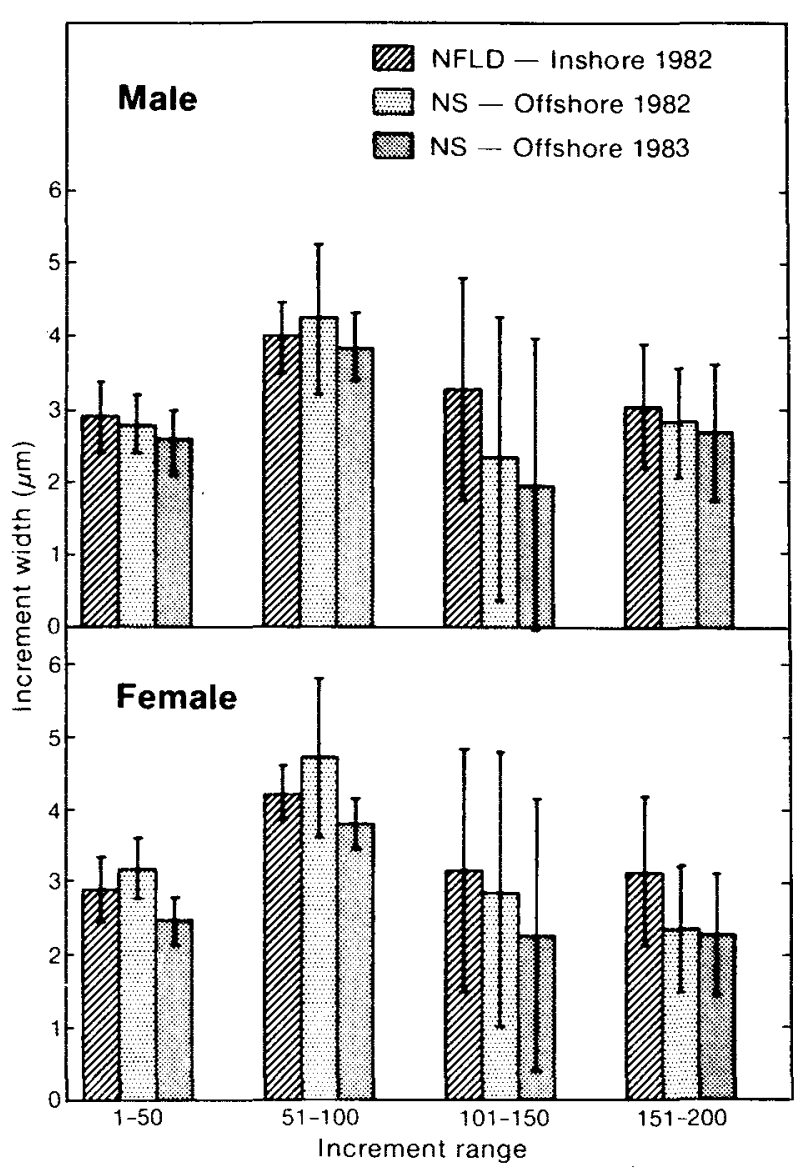

Fig. 10. Mean increment widths for all/. illecebrosus statoliths analyzed in Fig. 9. (Vertical lines indicate one standard deviation from the mean.)

inshore Newfoundland fishing grounds and the immigration of younger squid to the offshore areas of the Scotian Shelf. If increments are formed daily, the squid that were collected on the Scotian Shelf in November 1983, with increment counts ranging from 149 to 178 , could not have been present in the population that was sampled there in June.

Co-existence as well as the migration of distinct cohorts seem quite likely. Lange and Sissenwine (MS 1981), from polymodal length frequencies, reported that I. illecebrosus may spawn in late spring and early summer as well as during winter. Distinct size-groups commonly co-exist on the Scotian Shelf (Mesnil, 1977), and Squires (1967) noted the occasional occurrence of a group of small squid in southern Newfoundland wates during late autumn of some years. The statolith-ageing technique seems to be well suited for resolving problems associated with the presence of such cohorts.

Several aspects of age validation of I. illecebrosus need to be addressed in future studies. Efforts should be made to assess the age validation of squid in the field. This can be accomplished by examining the statoliths of previously-marked squid (tagged and treated with tetracycline or strontium) after recapture and comparing the increment deposition after marking with the known mark-recapture period. Rearing squid of known age would also be worthwhile to clarify the time of increment formation, but obstacles such as determining the food preferences of squid larvae have to be overcome.

\section{Acknowledgements}

We extend special thanks to J. Dawson of Hurley Fisheries Consulting, who aided in statolith preparation and the light microscope counts. We also acknowledge $E$. Dyer and $C$. Collings of the Atlantic Research Laboratory, National Research Council of Canada, for their assistance in the strontium labelling, and $\mathrm{C}$. Mason, M. Willison and S. Fry of Dalhousie University for scanning electron and fluorescence microscopy consultation. N. Balch, manager of the Aquatron Laboratory, Dalhousie University, provided temperature and salinity records and assisted in the rearing of squid larvae. T. Chandler of Hurley Fisheries Consulting designed the computer program for the graphics tablet and M. Primrose of Dalhousie University developed the light micrographs. Dr E. B. Brothers and $G$. $H$. Kruse kindly reviewed and commented on the manuscript.

The work was performed by Hurley Fisheries Consulting, Dartmouth, Nova Scotia, under contract to the Canadian Department of Fisheries and Oceans.

\section{References}

BROTHERS, E. B., C. F. MATHEWS, and R. LASKER. 1976. Daily growth increments in otoliths from larval and aduit fishes. Fish. Bull. U.S., 74: 1-9.

BROTHERS, E. B., E. D. PRINCE, and D. W. LEE. 1983. Age and growth of young-of-the-year bluefin tuna, Thunnus thynnus, from otolith microstructure. In Proceedings of the international workshop on age determination of oceanic pelagic fishes: tunas, bill fishes and sharks (p. 49-59), E. D. Prince and L. M. Pulos (ed.), NOAA Tech. Rep. NMFS, No. 8, $211 \mathrm{p}$.

CAMPANA, S. E., and J.D. NEILSON. 1982. Daily growth increments in otoliths of starry flounder (Platichthys stellatus) and the influence of some environmental variables in their production. Can. J. Fish. Aquat. Sci., 39: 937-942.

1985. Microstructure of fish otoliths. Can. J. Fish. Aquat. Sci, 42: 1014-1032.

DAWE, E. G. 1981. Overview of present progress towards ageing short-finned squid (I/lex illecebrosus) using statoliths. J. Shellfish Res., 1: 193-195.

DAWE, E. G., and P. C. BECK. 1985. Distribution and size of short-finned squid (Illexillecebrosus) larvae in the Northwest Atlantic from winter surveys in 1969, 1981 and 1982. J. Northw. Atl. Fish. Sci., 6: 43-55.

HATANAKA, H., A. M. T. LANGE, and T. AMARATUNGA. 1985. Geographical and vertical distribution of shortfinned squid (Illex illecebrosus) larvae in the Northwest Atlantic. NAFO Sci. Coun. Studies, 9: 93-99. 
HURLEY, G. V., and P. BECK. 1979. The observation of growth rings in statoliths from the ommastrephid squid, IIlex illecebrosus. Bull. Amer. Malcol. Union Inc., 1979: 23-29.

HURLEY, G. V., P. H. ODENSE, R. K. O'DOR, and E. G. DAWE. 1985. Strontium labelling for verifying daily growth increments in the statolith of the short-finned squid (IIlex illecebrosus). Can. J. Fish. Aquat. Sci., 42: 380-383.

LANGE, A. M. T., and M. P. SISSENWINE. MS 1981. Evidence of summer spawning of lllex illecebrosus (Lesueur) off the northeastern United States. NAFO SCR Doc., No. 33 , Serial No. N315, $17 \mathrm{p}$.

LIPINSKI, M. 1980. Statoliths as a possible tool for squid age determination. Bull. Acad. Pol. Sci., (Sci. Biol.), 28: 569-582.

MESNIL, B. 1977. Growth and life cycle of squid, Loligo pealei and Illex illecebrosus, from the Northwest Atlantic. ICNAF Sel. Papers, 2: 55-69.

MORRIS, C. C., and F. A. ALDRICH. 1985. Statolith length and increment number for age determination in Illex illece- brosus (Lesueur) (Cephalopoda, Ommastrephidae). NAFO Sci. Coun. Studies, 9: 101-106.

O'DOR, R. K. 1983. Illex illecebrosus. In Cephalopod life cycles (vol. 1, p. 175-199), P. R. Boyle (ed.), Academic Press, New York, N. Y., 475 p.

O'DOR, R. K., R. D. DURWARD, and N. BALCH. 1977. Maintenance and maturation of squid (Illex illecebrosus) in a 15-meter circular pool. Biol. Bull. Mar. Biol. Lab. Woods Hole, Mass., 153: 322-335.

PANTIN, C. F. A. 1960. Notes on microscopial techniques for zoologists. Cambridge Univ. Press. London, $486 \mathrm{p}$.

RADTKE, R. L. 1983. Chemical and structural characteristics of statoliths from the short-finned squid lllex illecebrosus. Mar. Biol., 76: 47--54

SQUIRES, H. J. 1967. Growth and hypothetical age of the Newfoundland bait squid, Illex illecebrosus illecebrosus. J. Fish. Res. Board Can., 24: 1209-1217.

TAUBERT, B. D., and D. W. COBLE. 1977. Daily rings in otoliths of three species of Lepomis and Tilapia mossambica. J. Fish. Res. Board Can., 34: 332-340. 